\title{
El asesinato en 1465 de Jehudá Alitienz, de la judería de Huesca
}

Eugenio BENEDICTO GRACIA

Cuando el Concejo de la ciudad de Huesca debía ejercer justicia, tras la presentación de una denuncia -«apellido»-, o bien de oficio, a través de los «procuradores» de la ciudad, tenía como fuente de información a los «deposantes»-personas que pudieran aportar datos sobre los hechos acaecidos. En el estudio de los protocolos notariales es frecuente encontrar noticia de las cuestiones más variadas que afectaban al orden ciudadano: robos, riñas, discusiones entre propietarios, muertes, etc. La mayor parte de ellas carecen de importancia y se reducen a algún pequeño párrafo en el que, simplemente, queda constancia de lo sucedido. Sin embargo, es interesante la «información en la muerte de Jehudá» ${ }^{1}$, no sólo por el hecho en sí, sino, sobre todo, porque nos permite saber algo más sobre la vida cotidiana de la ciudad, así como sobre las relaciones dentro de la comunidad judía en la que no faltaban duros enfrentamientos entre sus miembros. A partir de la lectura de los documentos que presento parece que no puede mantenerse el criterio de que el periodo que va de 1458 a 1479 fuera de paz para la aljama judaica de Huesca ${ }^{2}$.

\footnotetext{
1 Infra, Apéndice, n. ${ }^{\circ} 15$.

2 Y. F. BAER, Historia de los judios en la España cristiana. Trad. de J. L. LACAVE RIAÑo (Madrid 1982) pág. 686.

Sefarad 65 (2005) págs. 287-325

(c) CSIC

ISSN 037-0894
} 
Podemos, además, conocer la actuación del Concejo, la cual se ajustaba a la doctrina jurídica basada en los estatutos que tenían su origen en las antiguas «ordinaciones» y que cada año, de acuerdo con la experiencia acumulada, modificaban «sabios en dreyto». El protagonista en este estudio es Jehudá, hijo de Baruch Alintienz y de Bonadona Avinardut. Respecto a los antecedentes familiares de Jehudá, sabemos que en el lejano 1164 aparece mencionado un Salamón Alantienz $^{3}$; para el siglo XIV conocemos otros Alintienz, y en la reunión de la aljama de 30 de octubre de 1402 figura otro individuo. Y así se sucede el apellido sin interrupción hasta los días de la expulsión. Uno de los últimos Alintienz que recojo es quemado por la Inquisición en junio de $1490^{4}$. En lo que se refiere a la familia Avinardut ${ }^{5}$, Del Arco ya da algún dato de 1211, y sabemos que en 1359 otro Avinardut distribuye entre los judíos las obras de reparación de las torres, muros y albacares de la muralla de la ciudad, y que en 1398 consta el examen de un Jucé y Hanín Avinardut para físicos en Huesca $^{6}$.

Baruch Alintienz, el padre, es hombre de negocios y comerciante. He podido reunir entre 1438 y 1449 noticias de 136 comandas y algunas juras que realiza. Participa en el mercado de la lana desde 1437 a 1446 de forma importante y, asimismo, negocia con corambres (pieles); en un documento de 3 de agosto de 1423 figura que tiene una botiga de trapero por la que, el 6 de junio de 1442, paga un alquiler; en 1423 es clavario de la aljama, lo que muestra su situación clave dentro de la comunidad judía.

La actividad de su hijo Jehudá es importante y variada. En 1445 aparecen sus primeras actuaciones económicas como testigo en comanda y, ya como titular, el 11 de abril de 1446. El 17 de mayo de

3 R. DEL ARCO, «La aljama judaica de Huesca», Sefarad 7 (1947) págs. 271-301.

4 Y. F. BAER, Historia de los judios, págs. 819-821.

5 R. DEL ARCO, «La aljama judaica de Huesca».

6 Archivo de la Corona de Aragón [=ACA] reg. 310, fol. 27, apud Y. F. BAER, Die Juden im Christlichen Spanien. Aragonien und Navarra (Berlin 1929) n. ${ }^{\circ} 70$, pág. 276. 
1447 firma una cancelación de una comanda de su padre; y a partir de 1451 , y hasta su muerte en 1465 , lo encontramos como prestador. En total, he contabilizado ochenta y siete comandas. Además, se dedica a la compra de lanas, viñas, campos, casas, etc.; firma albaranes como heredero único de su padre; alquila campos; y da a trehudo una «cantarería» y unas casas, tanto en la judería (en el Coso) como en la plaza de la Alquibla. Actúa también como procurador de Mira el Nieto, su mujer.

A continuación, doy noticia de los quince documentos (que publico en apéndice) -entre 1456 y 1465 - que ponen de manifiesto el acontecer de la vida de Jehudá. Dichos documentos, además, ofrecen nuevas perspectivas acerca de esta comunidad, aún deficientemente conocida en este periodo clave, y arrojan luz sobre acontecimientos posteriores, más allá del ámbito local, por lo que creo que pueden ser útiles en ulteriores investigaciones.

El 3 de febrero de 1456 Jehudá forma una «companya» con Miguel de Cravexas y Johan de Ciresuela para desarrollar diversas actividades económicas (1), siendo importante señalar la confianza que Jehudá tiene en sus socios cristianos ante la demora del pago de las cantidades que les correspondía abonar como socios de dicha «companya». La constitución de compañías comerciales era muy frecuente, pudiéndose documentar una primera en 1426, una «botiga de trapería» integrada por Simuel Erica y Betrán de Sessa, de Huesca ${ }^{7}$. En 1459, forman una compañía Eleazar Adder y Johan de Ordunya, en Tabernas, para explotar en común las tierras de ambos ${ }^{8}$. En 1463 se crea una compañía entre Háym Bacar, «jodío perayre» de Huesca, y un cristiano para desarrollar la actividad de «tondedoris», con unas características muy peculiares ${ }^{9}$. Así podríamos seguir citando la constitución de otras muchas compañías que, en un futuro próximo, espero dar a conocer.

AHPH, prot. 177 , fol. 226-229.

8 AHPH, prot. 197, fols. 20-25.

9 AHPH, prot. 222, fol. 20. 
El 12 de octubre de 1456 se firman los «Capitoles entre D. Martín López de Zeresuela et Geudá Alitienze ... arrendadores de la carnicería e sinsa de carnes de la judería de Huesca, e Jacop Anocha ... collidor et receptor ...»(2): La sisa era una contribución fiscal indirecta que se cobraba sobre géneros comestibles. Su práctica se documenta tempranamente en Aragón. Pedro IV la suprime en 1372, pero en 1429 fue de nuevo impuesta, pese a su impopularidad. El documento que nos ocupa, en el que los arrendadores son dos cristianos y Jehudá, nos ofrece detalles precisos del estricto control y la contabilidad de la carnicería ${ }^{10}$.

El 25 de mayo de 1460 Bonadona Avinardut, madre de Jehudá, acepta la cesión a trehudo perpetuo de unas casas en la plaza de la Alquibla a favor de Guallart de l'Abadía (3). En el documento, la madre da el consentimiento y transfiere todos sus derechos a su hijo; parece ser que Bonadona mantiene la tutela sobre el hijo, por lo menos en cuanto al patrimonio se refiere. Como era habitual, se da la «carta de gracia», derecho a que el vendedor recupere su antigua propiedad siempre que esté al corriente del pago de las anualidades (derecho de «luición»).

El 15 de octubre de 1460 Jehudá vende a su madre Bonadona todos sus bienes (4). El inventario de estos bienes es exhaustivo, dándonos a conocer un importante patrimonio material. Es interesante la relación de deudos, comandas, trehudos, censales y otros contratos a él debidos, documentados y sin documentar, por cualquier título, caso o razón en el Reino de Aragón. Es legítimo preguntarse por los motivos de esta venta. ¿Estratagema de tipo fiscal? ¿Encubre subterfugios que pueden dañar los intereses de la aljama y que su notario, Jucé Papur, ve con malos ojos? El monto de la venta es muy importante, «quatro mil florines de oro en oro et de buen e dreyto peso del Regno de Aragón».

\footnotetext{
10 Véase al respecto J. L. LACAVE, «La carnicería de la aljama zaragozana a fines del siglo XV», Sefarad 35 (1975) págs. 3-35.
} 
En 19 de noviembre de 1460 se fecha una «obligación» que documenta una sorprendente y desmedida afición de Jehudá por el juego y, a la vez, su compromiso de no jugar por «tiempo de dos anyos» (5). Otro judío, mozo, llamado Jucef, judío de Huesca, se obliga el 27 de septiembre de 1397 ante su patrón cristiano a no jugar «a ningún juego que dinero hi avrá, por tiempo de cinquo anyos ... ni por spacio de diez leguas alderedor». Son estos los dos únicos casos de «obligación» que he encontrado.

La corte del Justicia prohibía el juego, aunque lo toleraba. Lo que sí impedía es que en las casas de juego participaran juntos cristianos, judíos y moros. Esto suponía que, en teoría, cada grupo debía practicar el juego de forma independiente ${ }^{11}$. Las autoridades rabínicas apartaban al jugador reconocido de cargos de responsabilidad, tales como juez, testigo, etc., y lo tenían por tramposo y mentiroso, llegando a considerar las ganancias del juego como producto de robo. También excluía a los jugadores de determinadas funciones religiosas y sociales: no podían subir a la tribuna sinagogal a leer la Torá y en la aljama de Huesca se les vedaba su pertenencia a la cofradía de Cabarín. Consideraban que el juego podía llegar a malgastar el patrimonio familiar. Por eso se prohibía totalmente, aunque se podía jugar en días medio festivos, bodas, etc., destinando las ganancias a obras benéficas. Las limitaciones que para el ejercicio de cargos en la aljama se establecían para los jugadores pueden ser el motivo por el que Jehudá se compromete a no jugar durante un tiempo determinado y así poder optar a ser elegido para alguno de ellos.

El 30 de abril de 1461 se firma ante el notario cristiano un «compromis» para llegar a un acuerdo entre la familia Xuén -muy importante en la aljama-, Jucé Alcastiel y Astruch Cazez, contra Bonadona Havinardut y su hijo Jehudá sobre ciertas «paraulas e injurias, danyos ... [que] havían concorrido entre ellos»(6). Alguna otra vez

$"$ Fenómeno estudiado por A. Blasco Martínez, «Los judíos de Aragón y los juegos de azar», en Homenaje a la Profesora C. Orcástegui Gros. Aragón en la Edad Media, XIV-XV (Zaragoza 1999) vol. I, págs. 91-118. 
sucede que judíos recurren ante la corte del Justicia, pero lo usual es que dichos recursos sean devueltos a la aljama por ser «cosas entre judios». Este documento es testimonio de tensiones dentro de la aljama, aunque desconocemos el contenido exacto del litigio que enfrentaba a esas familias.

El 25 de junio de 1461 «Pedro de Urrea, portero del senyor Rey, diputado al servicio de la tresorería ... [ha] recibido de vos, Jehudá Alentienz ... seyscientos trenta e siet sueldos ... de nos salarios» (7), aunque desconozco a qué salarios se refiere. Tres días después, el 28 de junio, se firma un «compromis» entre Ramón de Sangüesa y Jehudá por «sobre qualesquiere companyas de mercaderías, empréstamos de dineros y florines ... lexaron en poder de Pedro de Gan ...» (8). Al no haber árbitro judío, queda bajo criterio del cristiano como único «componedor». Veremos a Ramón de Sangüesa como informador en 1465 de parte de Jehudá.

Ya en el 20 de septiembre de 1461 se ofrecen Mossé Rondí, Alazar Ampinaz e Simuel Avinjafia como «caplenadores» (es decir, garantes) de Jehudá (9), preso entonces por el honorable Martín de Exea, y designan procuradores para gestionar en Zaragoza su libertad. El sistema de responsabilidad por un preso era normal, fijando la corte del Justicia las condiciones. El preso podía, entonces, quedar prisionero en su propia casa (o en la casa del «caplenador»), sin poder salir a la calle; o bien se le permitía atender sus negocios en la ciudad o fuera de ella, siempre bajo la responsabilidad del garante, y desplazarse por todo el reino con la condición de presentarse en la Corte a los cinco días de ser requerido. Si el «caplenado» no cumplía las condiciones, inmediatamente el responsable tenía que acudir a la Corte a desentenderse de la custodia del individuo en cuestión. A manera de ejemplo, sirva la siguiente ilustración:

1490. Carta pública de muerte. Die 29 marcii, anno M$^{\circ}$ CCCCLXXXX, Osce.

Dentro de hunas casas, sitas en la judería Osce, de Simuel Argellet, judío de la dita aljama, en huna cambra de las ditas casas, en un 
lecho ... staba un cuerpo, siquiere cadáver, muerto por amortallar, la cara escubierta. En presencia de mí, notario ... fue personalment constituído Simuel Mucanuno, judío Osce, así como caplenador por la Inquissición de la persona de Mossé Cocumbriel ... por la visión de su cara, por la vista aquélla, conocimos yo, notario ... estar el dito Mossé Cocumbriel e no otro en lugar de aquél et haver rendido su ánima e fuído sus días ... fecit instrumentum publicum, fiat large. Testes: Johan d'Otal, Johan de Madil e Mossé Leví, judío texedor Osce ${ }^{12}$.

Suponiendo, como puede desprenderse del texto anterior, que Simuel Argellet y Simuel Mucanuno eran los caplenadores de Mossé Cocumbriel, vemos que un judío podía, incluso, morir fuera de su casa si se encontraba en situación de caplenado.

Un albarán del 13 de diciembre de 1461 a favor de Jehudá señala «aver ... recibido de vos don Ramón de Sangüesa ... aquellos dos mil sueldos ... sacados en pública forma» ${ }^{13}$ (10). El dinero que en esta ocasión había prestado Jehudá es una cantidad considerable, lo que hace suponer que disponía de medios económicos abundantes.

El 18 de noviembre de 1464 Jehudá vende sus bienes -unas casas con corral- en la judería, en el barrio de los aldarbes, por seiscientos sueldos, y el comprador, Johan Alamán, se las da en trehudo por cuarenta y cinco sueldos al año (11-12) ${ }^{14}$. El 4 de diciembre de 1467 los herederos de Jehudá recompran la propiedad. Sabemos por un albarán incluido en el protocolo $\mathrm{n}^{\circ} 14$ (9 de junio de 1466) que dichos herederos, tutelados por Acach Alentienz, eran Baruch, Abram, Jucé, Simuel y Bonadona ${ }^{15}$.

El 30 de enero de 1465 se fecha el «jurament» con la «halmulacanda» ${ }^{16}$ en la sinagoga mayor de la judería (13). Es de resaltar que

12 AHPH, prot. 364, fol. 32v.

13 Sacar en pública forma consistía en reclamar las deudas ante la Corte.

${ }^{14}$ Esta venta aparece reflejada, con la misma fecha, en dos protocolos, $n{ }^{\circ} 11.766$ y $\mathrm{n}^{\circ}$ 101, el segundo de los cuales va seguido de la «carta de gracia».

${ }^{15}$ Mira Lo Nieto, mujer de Jehudá, aparece citada, con su cónyuge, en una procuración de febrero de 1453.

${ }^{16}$ No he logrado averiguar la etimología y significado de este término. 
en la correspondiente lista constan exclusivamente los judíos que ejercían el préstamo, figurando citado entre ellos Jeudá Alitience. Llama la atención la aparición en esta lista de mujeres judías prestamistas, probablemente viudas que seguían los negocios de sus maridos ${ }^{17}$. La práctica crediticia estaba muy generalizada y, pese a que a los cristianos les estaba prohibida, encontramos que tanto clérigos como laicos la ejercían. En 1405, una Francisca López de Huesca presta abundantemente a judíos, e igualmente el «obispo de Guesca» Anthón de Spes presta, el 12 de marzo de 1484, seiscientos sueldos a «Salamón et Jucé Raenas».

El 17 de abril de 1465 Jehudá pide auxilio ante el Justicia y los jurados (14) ${ }^{18}$. En su denuncia, señala que quieren damnificarlo, siendo la contestación de éstos que «como los jodíos sían regalías del senyor Rey e singularment como el dito Jehudá sía adelantado e oficial en el anyo present de la dita judería, que ellos no pasarían esto ...». La condición que le pone el Justicia es que diga quiénes son esos cristianos, condición que no puede cumplir, por lo que cancela la denuncia «e requirieron a mí, notario, que lo cancellase». No obstante, ante la advertencia de los jurados que le dicen que «sciertos christianos así de pie como de caballo aviesen esperado ... por dampnificarlo ...», responde que ni sus primos, ni él, ni Aym Almaxech los conocen, «que el día de Pascua ... a la noche, la una noche lo corrieron con capas». Y así queda el asunto.

Sin embargo, en el 11 de julio de 1465 aparece fechada una «información en la muerte de Jeudá» (14). Esta información se acomodaría, en mi opinión, a lo establecido en el estatuto de la ciudad ${ }^{19}$, del que no se han encontrado antecedentes, siendo el más próximo al asesi-

\footnotetext{
17 Trata con detalle el juramento D. Romano, «El estatuto de Huesca (1307) sobre la usura judía», en XV Congreso de Historia de la Corona de Aragón (Jaca, 1993). Actas, crónicas y ponencias. El poder real en la Corona de Aragón (siglos XIV-XVI) (Zaragoza 1994) págs. 257-272.

18 R. DEL ARCO, «El municipio oscense de antaño», en Diversos trabajos. Filosofía y Letras (Zaragoza 1936).

19 AHPH, sign. 1327 (Carpeta del Justicia), Estatuto de la ciudad de Huesca, 1468.
} 
nato de Jehudá el contenido en la carpeta del Justicia de 1468. Los estatutos regían todo lo que podríamos llamar hoy Orden Público de la ciudad. También eran denominadas estatutos las normativas referidas a todas y a cada una de las actividades de carácter público: panaderías, carnecerías, pastos, etc., posponiendo en muchos casos el orden foral. La aplicación de un estatuto obligaba a tomar declaración a todo aquel que conociera algún aspecto del suceso. La declaración se efectuaba ante el jurado prior o su lugarteniente, que era la mayor autoridad en la ciudad en cuanto al orden establecido. A continuación, agrupo las declaraciones de los comparecientes que figuran en el documento que nos ocupa según su credo religioso.

\section{JuDíos}

Acach el Nieto, pariente de la mujer de Jehudá, «juzge que yes de la aliama ...». Jehudá le había pedido que «fiziese las notas de Jucén Papur, judio e notario ... haviese algunos actos pertenecientes al dito Jeudá ... fue a casa del dito Papur ... era allí e malignoso l'uno contra l'otro e se dixieron de feas paraulas ... Papur e de feyto ... Jucé dixo que no lo siguraría porque él era enemigo suyo de sangre ... Pero creye según las congituras creye queste Papur meresce culpa en la muert del Jeudá e tal fama publica yes en la ciudat de Huesca».

Jacó Cohén dice que «este Jucé Papur desafio al Jeudá ... un ginet quiso matar al dito Jeudá ... que creye verdaderament que a tracto d'este Papur yes muerto Jeudá ...».

Aym Figel añade que «ya ha deposado en poder de Martín Navarro».

Nicín Sanoga, «nichil».

Acach de Pina señala que «dixo Abrayme Alintienz: más valdría que Jeudá Alintienz morise a mano de sus parientes que no a manos de un lacayo ... que el fillo del ferero de Loarre lo habia muerto». 
Nicín Anín, alias Cubero cree que Jehudá «e[s] muerto a tracto de Jucé Papur e de Azerián e de su muller ... oyó dizir qu'este Salomón Alintienz lo avia corrido con la capa gorga».

Astruch Cazez, «dize que vió muerto a Jeudá Alintienz ... lo ha muerto el fillo del ferero de Loarre e que ha oydo dezir que Rabí Jucé, el fillo del Blanco e Salamón Alitienz hi ha cabido tracto ... El dayán tenía Cort e vino Jeudá e posóse cerca del dayán e dixo: ... me ha corido mi nieto Salamón Alintienz, con la capa gorga rancada, por quererme matar». «Rabí Jucé le dixo al desposant: ... en toda manera del mundo este Jeudá avía de morir e que no avía otro remedio ...».

De las declaraciones de los judíos se desprende la existencia de enfrentamientos entre ellos de los que son responsables el nieto de Jehudá y rabí Jucé Papur. Si el notario, al referirse a «su nieto», dice bien, nos encontraríamos con que Jehudá debió de haber contraído un matrimonio anterior del que procedería este nieto ${ }^{20}$.

\section{CRISTIANOS}

Audans, «no sabe res».

Don Johán de Ascaso, notario, «creye que segund las conginturas creye que el Papur haya cabido».

Maestre Bernart de Aras señala que «había zizanias entre Jucé Papur e Jeudá ...».

\footnotetext{
20 Ante la duda de que pudieran existir dos Jehudás, repasé infructuosamente todos los protocolos notariales que tengo recogidos. En 1477 aparece por primera vez Habram Jehudá, «fillyo de Geudá Alentienz», como prestador, y al año siguiente, como recipiendiario de una deuda que tenía Johan de Cidiellyo con su padre, figurando como tutor Acach Alitienz. A partir de entonces se señala en varias comandas que el hijo es «fillyo de Gehudá quondam». En 1483 aparece citado su hermano Jucé, «fillyo de Gehudá, quondam». Ante la duda de que Salamón fuera, o no, nieto de Jehudá, los dos declarantes Nicín Anín y Astruch Cazez no dicen, al nombrarle, que sea nieto.
} 
Martín Escudero testifica contra el hijo del herrero de Loarre y contra Rodrigo de Scasiella, herrero de Bardanena.

Don Ramón de Sangüesa había tenido un «compromis» con Jehudá, relatado antes. Quizá como viejo amigo de Jehudá quiere interceder ante Jucé Papur y le ruega aparte las diferencias. La suya es una información larga, y «sabe que avía sciertas diferencias entre Jucé Papur e Jeudá ... qu'ende firmoron compromís en poder de Sancho López e de Ramón de Xixena e porque no quisieron prorrogar el dito compromís, el Sancho López nestaba mal contento de Jehudá ... gentes del Sancho López ... lo querían danyar ... que el dito Jeudá lo avía burlado ... bariádole la palabra ${ }^{21}$... por amor del dito deposant dito que era contento y concordaron que todas las diferencias hi questiones ... venisen en poder del dito Sancho López ... el dito Papur no quiso firmar ...».

La declaración de Ramón de Sangüesa nos permite ver la trascendencia que tenía un «compromis». Habían convenido con Sancho López y Ramon de Xixena un arbitraje y parece ser que Jehudá no lo quería prorrogar. La prórroga podía referirse al plazo que se les concedía a los «arbitros» para su veredicto, o bien a la prórroga en el negocio que Jehudá y Jucé Papur pudieran tener. ¿Estaría Sancho López implicado en los negocios de Jucé Papur?

El 13 de julio de 1465 comparece Johan Beltrán, notario de Huesca, como procurador de Azerián Xuén y de Oro Xuén, presos en la cárcel común bajo la sospecha de haber participado en la muerte de Jehudá Alintienz, por «apellido» de Bernard, y como habían resultado inocentes de dicha acusación pide los libre de la prisión. El 16 de julio aparece la citación a Rodrigo d'Escasiella para que «dentro de ocho días pueda venir a excusarse, si excusarse puede, de la culpa que le dan en la muerte de Jehudá Alintienz». La situación de Rodrigo d'Escasiella, herrero de Bardanena, era de plena disposición del Justicia, y nadie podía comprometerlo en asunto alguno durante el

21 Es decir, «cambiándole la palabra», engañándole. 
plazo de ocho días concedido para su presentación. Es interesante observar que la autoridad del Justicia se extendía a toda la comarca, y no sólo a la ciudad de Huesca. El 20 de julio se presenta Rodrigo d'Escasiella acompañado de Sancho d'Ara y Guiralt Marta, quienes testifican a su favor ante el Justicia, declarando que la víspera de San Benito el acusado se encontraba en Bardanena, lugar próximo a Ayerbe.

Finalmente, me detendré en algunos aspectos de la vida de rabí Jucé Papur, que a pesar de ser, al menos moralmente, un individuo relevante en la muerte de Jehudá, no sufre, que sepamos, sus consecuencias penales. Se observa que participa en todo tipo de actividades hasta 1490 (veinticinco años después del asesinato), en que consta su encarcelación por otras causas ${ }^{22}$. Parece que Papur no tenía ascendencia oscense, sino que procedía de Jaca: un Alazar Papur aparece señalado como perteneciente a la aljama de Jaca en 1407, y en 1437 Abraham Papur es requerido por la corte del Justicia de Huesca para que pague el peaje de unas mercaderías que transportaba a Jaca.

La primera vez que aparece Jucé Papur en un documento de protocolos de Huesca es el 8 de mayo de 1460 como testigo en una comanda de Abraym Xuén. El 16 de mayo de 1460 es testigo en una «sentencia arbitral» por cuestiones entre Jucé Xuén, judío de Huesca, y Martín Pérez. El 9 de agosto de 1460 es testigo en una comanda de Simuel el Nieto, y el 21 de octubre de 1461 testifica en una comanda de Jehudá Alentienz, con el cual mantendría entonces relaciones cordiales. El 25 de marzo de 1464 es notario y aparece ante el dayán de la aljama por la guarda de un preso, y se repite con frecuencia como testigo en diversas comandas. A partir de 1464, aparece como prestador en dinero y cereal. Durán da noticias de sus actividades comerciales, calificándolo de escriba y notario ${ }^{23}$. El 19 de diciembre de 1467 «Jucé Papur, fillo del sabio rabí Papur», es testigo en un albarán de Sentó y Bonafós Argellet, y otro hijo, Abram Papur, es testigo en una comanda del 7 de abril de 1478 en la que se titula «studiant».

22 Y. F. BAER, Historia de los judíos, págs. 817-820.

23 A. Durán Gudiol, La judería de Huesca (Zaragoza 1984) pág. 74. 
Hay un entenado, Jucé Ambrom, que en 1490 reclama la parte de los bienes de su madre, Soli Alfrangí, judía, «muller» que fue de rabí Jucé Papur, «compdenado» por la Inquisición por el asunto de Juan de Ciudad. Es una lástima que la falta de documentación impida saber el final de este suceso, aunque hay que celebrar que, con la existente, se haya podido conocer, con cierto detalle, este hecho no cotidiano en la vida de la aljama de Huesca.

\section{APÉNDICE DOCUMENTAL}

1

\section{6, febrero 3. Huesca}

Capítulos de la compañía comercial entre Jehudá Alintienz, Miguel de Crabexas y Johan de Ciresola, desde el 1 de enero pasado, por un período de tres años.

AHPH, notario Juan de Ascaso, prot. 195, fols. 30v-32v

$$
\text { [30v] } 3 \text { febrero } 1456+\text { Jhs Xrs + }
$$

Mediantes los capitoles infrascriptos es feyda feyta companya entre Miguel de Crabexas, Gehudá Alintienz, judío e mí, Johan de Ciresola, menor, por tiempo de tres annyos, contaderos del primer día de janero más cerqua passado adelant que se conta annyo de mil CCCCL e seys.

[1] Primerament, es concordado entre los sobreditos que cada huno aya de meter en la companya siet mil e cincientos sueldos, los quales siamos tenidos el dito Miguel e yo Johan de Ciresola segunt más baxo parece más largament.

[2] Ytem más, es concordado entre los sobreditos qu'el dito Jehudá Elletienz, judío, sobredito aya de tener la bolsa de la companya durant el tiempo de la dita companya qu'es tres annyos. Et el dito Geudá sía tenido dar conto al dito Miguel et mí Johan de Ciresola cada annyo por fiestas de Nadal, requiriéndolo nosotros o aprés.

[3] Ytem más, es concordado entre todos los sobreditos que ninguno no pueda prender ni guanyo ni principal de la dita companya, mediant jurament 
e la pena infrascripta, sino con boluntat de los hotros, dentro el dito tiempo de los ditos tres annyos.

[4] Ytem más, es en condición entre todos los sobreditos que si el Miguel o yo, Johan de Ciresola, prenderemos dineros algunos de la dita companya, que dentro ocho días aprés que lo avremos preso, los ayamos de dar al dito Geudá de que seremos en ciudat o dar l'ende conto si algún finez por bentura ende avremos feyto dentro el dito tiempo de los ocho días.

[5] [31r] Ytem más, es concordado entre los sobreditos que durant tiempo de los tres annyos, ninguno de los sobreditos no pueda comprar nada, ni ninguna cosa, sino que todo lo que comprara aya a seyer pora la dita companya, sino en tal manera que comprase diez o quinze cafizes de trigo o vint o trenta cargas de uvas pora provisión de su casa o qualquiere hotra mínima cosa que fuese asimismo pora su previsión. Empero en aquesto no si entiende cosa alguna de los deudos que deven al dito Geudá, que no sían de la companya, segunt que más largament pareçe baxo en hotro capitol.

[6] Ytem más, es condición que si el dito Geudá recibía de los ditos sus deudos pan o hotra mercadería, que aquéllo sia del dito Geudá e de aquéllo pueda fazer a su boluntat, adverado con berdat seyer de sus deudos e no de la companya.

[7] Ytem más, si por ventura durant tiempo de los ditos tres annyos venía algún debat entre los sobreditos, que la dita conpanya no se pueda partir, sino que los todos ayamos a seyer a conoscimiento de don Andreu de Loyrés e de don Anthón Just, ciudadanos de la ciudat de Huesca e todos que siamos tenidos fazer e conplir todo lo que por ellyos será concordado, jus la pena infrascripta.

[8] Ytem más, es concordado entre todos los sobreditos que ayamos a fazer dos libros de la companya, de los quales livros aya a tener el huno el dito Geudá et l'otro el dito Miguel o yo, Johan de Ciresola, en los quales livros se ayan a scrivir todas qualesquiere [31v] conpras o bendas, deudos e expensas que faremos dentro el dito tiempo de los tres annyos. En los quales livros aya a scrivir el dito Geudá, de su mano, en el libro que tendremos el dito Miguel e yo, Johan, todas las sobreditas conpras o bendas, deudos e expensas que por la dita companya faremos. Et nosotros asimismo que los ayamos a scribir en el dito livro que tendrá el dito Geudá dentro ocho días aprés que seremos benidos de compras o bender, seyendo todos o aquel que avrá fecho el trato en el dito livro. Empero en la ciudat de Huesca con 
saqrament e con las penas infrascriptas e con aquesto queremos que qualesquiere scripturas que se trobarán en los ditos livros de mano de qualquiere de los sobreditos, así las que se trobarán de mano del dito Miguel o mía en el livro que tendrá el dito Geudá como de mano del dito Geudá en el livro que tendremos el dito Miguel o yo, Johan, que sían avidas en tanto como si eran de mano de notario e jurados todos los sobreditos, cada huno segunt su Ley de averlo por tanto e de no meter y ninguno de nosotros ni otri por nosotros pleyto ni questión, jus las penas infra scriptas.

[9] Ytem más, es concordado entre todos los sobreditos que qualesquiere cartas o contractos que faremos dentro el dito tiempo de la dita companya ara se digan a Miguel de Crabexas o al dito Geudá o a mí, Johan de Ceresola que todos tres ensenble reconoscemos encara que se digan a qualesquiere de todos nosotros seyer de todos tres. Empero seyendo trobados en los ditos livros de la dita companya scriptos segunt lo sobredito.

[10] Ytem más, es concordado en los sobreditos que por razón qu'el dito Miguel e yo, Johan de Ciresola, tenemos [32r] el cabal nuestro sobredito segunt consta alto en deudos e en poder de hotras personas qu'el dito Miguel e yo, Johan, prometemos et nos obligamos de darlos plegados e puestos en la dita companya d'aquí a Sant Miguel de setienbre o quinze días aprés primero benient. E qu'el dito Geudá nos aya a fazer albarán de res que le daremos de su mano cada begada que l'ende daremos. Empero es en condición que no le ayamos a dar sino de vint florines a suso por amor del saqrament sobredito e penas infrascriptas de los ocho días e que tal albarán de mano del dito Geudá aya a valer, asi como de suso es posado en lo de los livros, jus las penas infrascriptas.

[11] Ytem más, juramos todos tres, cada huno segunt su Ley, de bien e lealment aver nos en la dita companya e de guardar el proveyto de aquélla e de aredrar el damnyo e de trayer el guanyo todo en verdadera partición e de no defraudar de aquéllo, jus las penas infra scriptas.

[12] Ytem más, es concordado entre todos los sobreditos que si alguno de todos los sobreditos era trobado en defallymiento de frau de alguno de los capitoles, que encorra en pena de trezientos florines e de perjurio manifiesto, la qual pena sía dividida en tres partes, la mitat de la dita pena pora la companya e la hotra mitat que se aya a fazer dos partes, los setenta e cinquo florines pora los juges sobreditos et los hotros setenta e cinquo pora la obra de los muros de la ciudat de Huesca. 
[13] [32v] Ytem más, es condición si alguno de los tres contenrá enfirmar yudo por feytos de la companya que en tal enfermedat como aquélla, si gastara res se aya a meter en expensa de la companya fins en tanto que sía retornado pora poder trastiar e sía reforçado.

[14] Ytem, es concordado que no obstant el capitol sobredito que dize que ninguno no pueda gastar del principal ni del guanyo, que si por ventura contecía prenderne que cada vegada que avrá preso qualesquiere de los todos de aquí a complimiento de vint sueldos lo ayamos a dezir al bolsero o si él ne prenderá lo aya a dir a nosotros dentro ocho días aprés que priso los avrá, jus las penas sobreditas.

[15] Ytem, damos licencia todos tres ensenble que, no mudada sustancia, los pueda ordenar tanto e tan largament como será necesario e oportuno a utilidat de cada huna de las partes al notario las presentes capitoles testificant.

\section{2}

1456, octubre 12. Huesca

Capítulos para el arrendamiento de la carnicería y sisa de las carnes de la judería, constituídos entre Martín López de Zeresuela, Jehudá Alitienze y Jacop Anocha, alias De las Infantas, como recogedor, receptor y administrador de la sisa por un año.

AHPH, notario Juan de Ascaso, prot. 195, fols. 141v-143v

[141v] Capitoles feytos entre Martín López de Cirisuela e Jehudá Alitience e Jacob Hanoca.

[142r] Capitoles entre don Martín Lóppez de Zeresuela esqudero de la ciudat de Huesca et Geudá Alitienze, jodío, de la una part, arendadores de la carnizería e sinsa de carnes de la judería de Huesca e Jacop Anocha, allyas De las Infantas, collidor et rezeptor et ministrador de la dita sinsa e carnizería de suso dita, por los ditos Martín López et Geudá por tiempo de un anyo, que se contará a II días del mes hoctobre adelant por hun anyo seguient.

[1] Primerament, que el dito Jacop sia tenido de jurar et jura de feyto a Dios y a los santos diez mandamientos de la Ley de Muysés del levarse bien y lealment en la ministrazión recepción et colecta de la susodita carnizería y sinsa et de guardar ye todo aquel avanz proveyto y utilida quellya 
et de apartar de todo danyo e yntener sin quitar menoscabo que en aquellya se podiese ni pueda esdevenir e averse, et treballar en aquellya, ansin propiament con sin el danyo o proveyto fuese suyo propio, y esto jus pena de ser esperjurio del qual perjurio pueda ser aqusado sin si na qu'él cayere delant qualquiere juge o juges que los sobreditos rendadores convenir lo querán.

[2] [142v] Ytem más, el dito Jacop que suia tenido de yntimar e noteficar al dito don Martín López o Ramón de Sangüesa se ninguno jodío, vezino, abitador de la dita cyudat o otro qualquiere judío vendrá contra la dita rendazión o sinsa o carnizería en frau o danyo ynterés d'aquellya segunt tenor de los capitoles de la dita rendazión o si qualquiere otra manera dentro tiempo de 1 día aprés que a su noticia sia prevenido y a esto sía tenido a fazer el dito Jacop por vigor del saqrament por él prestado y en continent de la dita d'esperjurio.

[3] Ytem más, quel dito Jacop suia tenido dar buena, leal verdadero conto a los sobreditos rendadores de qualesquiere carnes que en la dita judería se matarán o se gastarán e por tenor de los capitoles de la dita rendazión son tenidos pagar sinsa, y ésto jus la pena de suso dita.

[4] Ytem, que suia tenido el dito Jacop de sábado a sábado a la nueyt, él y el carnizero que tallya o tallyará la carne de la carnecería sobredita, de dar bueno y leal conto al dito Geudá Alitienzer e de quinze a quinze días de día a domingo a domingo a los sobreditos don Martín López y Ramón de Sangüesa o el lunes siguient, y ésto por virtut del dito jurament por él prestado e de livrar el dito Jacop todos los dineros que sallirán de las ditas carnes o sinsas de XV a XV días, al dito Martín López jus pena d'esperjurio tirado lo que fiado avrá en lo que finado avrá a la fín del anyo o que más aprés aya de pagar, jus pena d'esperjurio.

[5] [143r] Ytem, qu'el dito Jacop suia tenido demandar collyir e exeguir e recebir sin quiere cobrar todos o qualesquiere deudos que la dita sinsa o carnes se farán o se fiarán, jus la dita pena d'esperjurio.

[6] Ytem más, el dito Jacop suia tenido que todas las tripas que sallyrán en la dita carnizería y en todo l'anyo de la dita rendazión del gastar o vender aquellyos al millor prezio que pora a proveyto de los sobreditos rendadores, jus pena de ser esperjurio. 
[7] Ytem más, el dito Jacop suia tenido en todo el sobredito anyo de alzar y guardar bien a proveyto de la desus dita companía los sevos, corambres que sallyrán en todo l'anyo de la dita rendación, y ésto jus pena d'esperjuryo.

[8] Ytem, los ditos Martín López y el dito Geudá suian tenidos dar al dito Jacop por los treballos qu'él avrá en reguir y atmenistrar la dita carnezería y sinsa por el dito anyo CCL sueldos e por collir los ditos deudos.

[9] [143v] Ytem más, el dito Jacop suia tenido que todas las carnes que se gastarán en todo l'anyo de la dita rendazión en la carnizería de los ditos judíos o en la dita judería, aquéllas pesarán y en su libro esqrevirán. Ansín mesmo, esqrevirán las corambres, sevos, pieles, cuernos de bueyes en su libro todo a útyl de los ditos rendadores e que los libros, rezeptas, datas de la dita rendación directament nin directa no dirá a ninguno ni mostrará los ditos libros jus pena d'esperjurio, syno a los ditos rendadores.

Die XII octobris, anno milésimo CCCCLVI. Fueron firmados los sobreditos capitoles por las ditas sobreditas e jurados devant dito Jacob e prestado en poder de Abrayme Altiffixí, garquiyán gamur por el dito Jacob. Testes Pero Lóppez de Latrás, Abrayme Altiffixí e Jacob Cohén, judíos Osce.

1460, mayo 25. Huesca

Bonadona Avinardut, madre de Jehudá y viuda de Baruch Alentienz, loa el alquiler de unas casas a Guallart de l'Abadí y a su mujer, en la plaza de la Alquibla.

AHPH, notario Juan de Ara, prot. 248, fols. 158v-159r

[158v] Carta pública de loación de Guallart de Labadía.

Eodem die. Bonadona Avinardut, judía, vidua, muller que fue de don Baruch Alentienz, quondam judío habitant en la ciudat de Huesca. Atendido e considerado que Jehudá Alentienz, judío ... fillyo mío, certificado de todo su dreyto, haya dado a treudo perpetuo ... a dreyto enfitéotico, con comiso, fadiga e otras condiciones a vos, Guallart de l'Abadía ... unas casas en la ciudat, en la placa de la Alquibla que confrontan con casas de Manuel Fagol e con casas del dito Jehudá e con tiendas e botigas de Abrayme Xuén e con la dita placa e con casas de Pedro Canero, con cargo de sixenta sueldos de 
trehudo perpetuo al dito Jehudá, pagaderos en dos tandas, la una por feria de Corpus Christi e la otra por el retorno de Sant Martín e con otras muytas condiciones ... constat por el contrato de la dita tributación, feyto en la ciudat de Huesca a quatro días del mes de febrero anno a Nativitate Domini millesimo $\mathrm{CCCC}^{\circ} \mathrm{LX}$... Yo dita Bonadona ... de mi agradable voluntat loho, aprovo e ratifiquo la dita tributación ... e no res menos ... transferesco a vos e en vos todo e qualquiere dreyto a mí tocant en aquellas ... Testes Pedro de Aragón, mercadero e Semptó Arueti, judío Osce.

Carta de gracia de los ditos Guallart e Lorenca ...

Los ditos Bonadona Avinardut e Jehudá Alentienz ... atorgaron de gracia special a los ditos Guallyart de l'Abadía e Lorença de Exal, cónyuges, que todos tiempos e cada e quando ellyos ... querrán comprar de ellyos ... los ditos sixenta sueldos del trehudo ... se obligaron de venderles a ellyos ... los ditos sixenta sueldos ... del trehudo ... por precio de mill sueldos dineros jaqueses ... Fiat large. Testes qui supra.

4

1460, octubre 15. Huesca

Jehudá Alitience vende todos sus bienes muebles e inmuebles, deudas, comandas, trehudos, censales y otros cualesquiera bienes, heredades, etc. por cuatro mil florines.

AHPH, notario Juan de Ascaso, prot. 197, fols. 161r-163v

[161r] Vendición die predicta.

Sia maniffiesto a todos que yo, Jehudá Alitience, judío habitante en la ciudat de Huesca, plenamente certificado e informado de todo mi dreyto, con tenor de la present carta pública de vendición siempre firme e valedera en tiempo alguno non revocadera de cierta sciencia e deliberada incussa e voluntat vendo e luego de present livro e desempero a vos Bonadona Havinardut, judía, muller que fuestes de Baruch Alitience, judío, quondam, madre mía a los vuestros e a qui vos querreyes, mandareyedes e ordenareyes, todos e qualesquiere bienes míos mobles e sedientes et qualesquiere deudos, comandas, trehudos, censales e otros qualesquiere bienes que por qual o qualesquiere persona o personas de qualesquiere Ley, stado, grado, preheminencia o condición sían a mí devidos e que a mí pertenescan et se acaten et pertenescer e acatar puedan e devan con cartas o sienes de cartas e por 
qualquiere otro dreyto, titol, caso, manera o razón, dentro del Regno de Aragón stantes et senyaladament los censales e las propiedades. Et serán casas et heredades infra principales de aquéllos e cartas de comandas, casas e heredades dius mencionadas, noticiadas e specificadas scriptas dentro de la ciudat de Huesca e términos de aquellos stantes.

Et primerament, de unas casas mías site en la judería en el barrio clamado de Amalbell, confronte con casas de Eleazar Alitience, con casas de Jucé Rahenas e con carrera pública, con todos bienes mobles de oro, argent, de lana, lino, cányamo, stopa, cotón, de seda; vacxiella vinaria, olearia de argent, de cobre, arambre, de allacón e de qualquiere otro metal e otros qualesquiere manificios et cubaxas de casa dentro de las ditas [161v] casas, stantes.

Ytem más, hun plantero mío sito a la Cerbatiella, término de la dita ciudat confronte con plantero de Mosé Adida, con plantero de Simuel Parexo e con plantero de Johan de Barluenga. Ytem, otro plantero sitiado en la Alguerdia, término de la dita ciudat, confronte con plantero de Johan de Pancano, alias Scartín, e con campo de Johan de Villa Real e con carrera pública.

Ytem, una tienda mía site en la ciudat de Huesca antedita a la Alquibla, confronta con carreras públicas de dos partes et con corral de Johan de Sepóluega, alias de Castiella, e con tienda de Ally Cellero.

Ytem más, dozientos e quatorce sueldos de cens que el concello de christianos de condición e aliama de los moros de la villa de Pina me fazen de cens o trehudo en cada hun anyo, por el tercero días del mes de febrero ensemble propiedad de aquéllos, que son tres mil sueldos dineros jaqueses segunt consta por carta pública de vendición a mí feyta en la dita villa, a tres días del mes de febrero anno a Nativitate Domini a milé[s]imo CCCCLVIII recibida e testificada por Pero Orta, havitant en la villa de Pina, notario público por ...

Ytem más, dozientos e quatorze sueldos, tres dineros e mea ensemble con propiedat e suert principal de aquéllos, que son tres mil sueldos que los justicia, jurados, concello del lugar de Alcovierre me fazen por el día de cabo de anyo, según consta por carta pública de vendición que firmasse en el dito lugar a XXVII de diciembre anno a Nativitate Domini milésimo CCCCL quinto. 
Ytem más, dos mil sueldos dineros jaqueses [ilegible] Jucé de Huerto, Abraym Guerrero, Audalá de Haqua, Alfarag e Jahel de las Cambras, moros de Tierc, atorgan tener en comanda de mí, dito Jeudá según consta ... en Tierc a XXVIIII de agusto anno $\mathrm{M}^{\circ}$ CCCCLII [162r].

Et de sí, todas e qualesquiere otras heredades de campos, vinyas, sotos, huertos, hortales, yermos e poblados dentro de la dita ciudat e términos de aquélla, sitiados e sitiadas, conoscidos e conoscidas e por conoscer e otros qualesquiere deudos e cartas las quales e los quales quiero haver aquí por expresos nombrados e bien, assí como si por sus confrontaciones e limitaciones e con la presente carta pública de vendición fuesen nombrados, confrontadas, limitadas, assi como las ditas confrontaciones concuerdan, encarran et de part de cada una part las casas de suso confrontadas con todos los otros bienes mobles, vaxiella vinaria, olearia, de cobre, arrambre, allaton, de argent e de qualquiere otro metal. Yo, dito Jeudá vendo ... a vos, Bonadona Havinardut, madre mía ... vendo et a vos et a mí bien plazible de quatro mil florines, de oro en oro et buen e dreyto peso del Regno de Aragón ... reconosco haver havido et en poder mío haver recebido ... seyer pagado ... con la aliara ... renuncio a las cosas sobreditas ad aquella ley que ayuda a los vendedores decebidos e enganyados en las vendiciones feytas por menos de la mitat del justo precio ... oblígovos todos mis bienes ... por mayor seguridat fago quinyán gamur meansan $[s i c]$ en poder de Acac Alguer, judío, teste diuso scripto.

Feyto fue aquesto en la ciudat de Huesca a XV días del mes de octobre anno a Nativitate Domini miléssimo CCCCLX. Presentes teste fueron d'ésto don Johan Serra, ciudadano, Acac Alguer e Jehudá Almaxech, judíos, habitantes en la cidat de Huesca.

1460, noviembre 19. Huesca

Jehudá Alitience adquiere la obligación de no jugar a ningún juego por tiempo de dos años.

AHPH, notario Juan de Ascaso, prot. 197, fol. 191v

[191v] Obligación. 19 Noviembre 1460.

Die predicta. Yo, Jeudá Alitience, judío habitant en la ciudat de Huesca, atendient e considerant que yo fago de cada día abuso de jugar inmodera- 
dament en grant danyo mío e de mi casa e detriment de mi honrra, prometo e me obligo por tiempo de dos anyos continuament contaderos del present día e hora que la present carta yes feita, de no jugar por mí, ni otro por mí, ni yo jugar por otro alguno a ningún juego que de ninguna manera sía, et sto dius pena de quince florines, devidideros en tres partes yguales, los cinquo por al senyor Rey, los otros cinquo florines pora l'acusador y los otros cinquo por al spital de la judería de la dita ciudat. Et más juro por Dios e a los diez mandamientos de la Ley de tener lo sobredito, dius pena de hérem y nidduy de atorgar que si le será demandado por su madre o personas suyas si habrá jugado, que dirá la verdat.

Item más, juro que no dará penyoras de cosa ninguna e sienes voluntat de mi madre. Testes Johan de Viturián e Acach Alguer, judío Osce.

\section{6}

\section{1, abril 30. Huesca}

Jucé, Abrayme, Azarián y Acac Xuén (hijo de Abrayme), Jucé Alcastiel y Astruch Cazet se comprometen con Bonadona Havinardut, madre de Jehudá, a aceptar una sentencia arbitral por causa de "ciertas palabras», injurias, daños e intereses que entre Jehudá y los Xuén, Alcastiel y Cazet, habian surgido.

AHPH, notario Juan de Ascaso, prot. 198, fols. 62v-63v

Compromis.

[62v] Die XXX mensis aprilis. Como pleytos, questiones et debates fuessen et sperassen sert civiles et criminales entre Jucé Xuén, Abrayme Xuén, Azarián Exuén e Acac Xuén, fillo del dito Abrayme Xuén, Jucé Alcastiel e Astruch Cazet, judíos habitantes en la ciudat de Huesca, de la una part, demandantes e defendientes et Bonadona Havinardut, judía, muller de Baruch Alitience, judío quondam habitant en la ciudat, madre de Jeudá Alitience en, e sobre ciertas paraulas e injurias, danyos et intereses que entre el dito Jeudá e los sobreditos Jucé, Abrayme, Azarián, Acat Xuén, Jucé Alcastiel e Astruch Cazez havían concorridos entre ellos, intervinientes amigos et buenas personas para bien de paç e concordia, todos sobreditos de suso nombrados por su ser, e la sobredita Bonadona Avinardut, madre del dito Jeudá, en su nombre propio et como persona conjunta del dito Jeudá por su part, e del dito Jeudá, componioron, comprometioron e absueltament lexaron si quiere comprometer en todos e cada unas questiones e en sobreditas en 
poder [63r] de los honorables don Bertholomé Salvador, scudero de maestre Sentó Cavatierra, et de Salamón Hambrón, judíos habitantes en la ciudat de Huesca, assí como en árbitros arbitradores ... dieron pleno et bastante poder de dar, sancionar, determinar e todos concordes d'aquí a por todo el mes de mayo primero viniente e mes de medio ... e tachar salario por assí e al notario e prometieron, e se obligaron de haver por firme, dius pena de dozientos florines e devidideros en tres partes yguales, la primera para el senyor Rey, la segunda pora los árbitros e en la tercera por la part obedient. Et a tener, complir e se obligaron sus personas e todos sus bienes ... juraron a los mandamientos de la Ley en poder de Gentó [N]Atán, judío teste, prestoron quinyán gamur tener, complir e seguir qualesquiere que por los ditos árbitros fuese pronunciado, sentenciado dius pena de perjurios [63v] públicos e manifiestos, dius pena de hérem y nidduy.

Presentes testes fueron d'esto, Miguel de Biniés, Gentó Natán e Cazón Leví, judíos Osce.

Die XXII madii. Los sobreditos Bertholomeu Salvador, maestre Sentó Cavatierra e Salamón Hambrón, judíos árbitros, comprometieron en prorrogar d'aquí por todo el mes de julio primero venient.

Testes, Johan Calbo e Hacén Aybarí e Sentó Cavatierra, judíos Osce.

7

1461, junio 25. Huesca

Pedro de Urrea, portero del Rey, otorga albarán de 637 sueldos de sus salarios a Jehudá Alentienz.

AHPH, notario Juan de Ara, prot. 96, fols. 174v-175r

[174v] Albarán de Jehudá Alentienz.

Die XXV junii, anno quo supra, Osce. Yo, Pedro de Urrea, portero del senyor Rey, diputado al servicio de la tresorería, en el dito nombre atorgo haver havido e en poder mío realment de feyto recebido de vos, Jehudá Alentienz, judío habitant en la ciudat de Huesca, son a saber seyscientos trenta e siet sueldos dineros jacceses. Et más me atorgo seyer contento de mis salarios e por aquesto yes verdat, quiero que por el notario infrascripto vos sía feyto el present público albarán, firme e siempre valedero e en tiempo alguno non revocadero, dius obligación de todos mis bienes, large ...

Testes, Johan de Oteyça, alias Soguero, Ramón de Pargada, bolsero, e Acach Alguer, judío Osce. 
1461, junio 28. Huesca

Ramón de Sangüesa y Jehudá Alentienz dejan a Pedro de Gan como árbitro en cualquier clase de pleito que surja entre ellos durante el mes de agosto próximo.

AHPH, notario Juan de Ara, prot. 96, fols. 182v-183r

[182v] Firma de compromis de don Ramón de Sangüesa e de Jeudá Alentienz. Eodem die, Osce. Como pleytos, debates, questiones e controversias así civiles como criminales yeran e speraban seyer entre los honorables don Ramón de Sangüesa, ciudadano de la ciudat de Huesca, de la una part, agent e defendient, et Jeudá Alentienz, judío habitant de la ciudat, de la otra part, asímatex agent e defendient. Et sobre qualquiere conpanyas de mercaderías, empréstemos de dineros e florines, cartas de comanda, de deudo o por qualquiere otro capitol, dreyto, manera o razón, de todo el tiempo pasado, entro el present e infrascripto día e por los dependientes incidentes e emergentes de aquéllos. E de cada una, por tanto, las ditas partes comprometieron e absueltament lixaron todos los ditos pleytos ... en poder ... de los honorables Pedro de Gan, ciudadano de la ciudat de Huesca ... el qual pueda dezir, sentenciar, pronunciar, determinar sobre los ditos pleytos ... d'aquí por todo el mes de agosto primero viniente. Et prometieron e se obligaron aceptar, loar, aprovar ... cosa que por el dito árbitro será dito ... dius pena de trezientos florines de oro, dividideros en tres partes yguales ... Renunciaron ad árbitro de buen varón, beneficio de apelación e renunciación a su judge de cada uno de ellos ... fiat large.

Testes, Felip de Sepúlveda, civis, Goncalbo de Mora, texidor, e Aym Gastón, judío Osce.

\section{9}

\section{1, septiembre 20. Huesca}

Mossé Rondí, Alazar Ampinaz y Simuel Avinjafía, judios de Huesca, nombran procuradores a los zaragozanos Domingo de Santacruz. Bartolomé de Castaneta y Juan de Biscuera, y al maestre Selamón Hanayut, judio de Calatayud, para librar de la «caplenza» a Jehudá en la que ellos están comprometidos.

AHPH, notario Juan de Ascaso, prot. 198, fols. 131r-v 
[131r] Procuración.

Die XX mensis setenbris. Nos, Mossé Rondí, Alazar Ampinaz e Simuel Avinjafía, judíos, habitantes en la ciudat de Huesca, assí como caplenadores de la persona de Jeudá Alitience, judío habitant en la ciudat de Huesca, preso por honorable Martín de Exea, portero de la cambra del senyor Rey de Aragón, agora bien adveturadament regnant. Femos procuradors a micer Domingo de Santacruc, don Bartholomeu de Castaneta e don Johan de Biscuera, habitantes en Caragoca, e a maestre Salamón Hanayut, judío habitant en la ciudat $[131 v]$ de Calatayut, a todos ensemble, e a ssaber, a presentar, dar, restituir e livrar la persona del dito Jeudá devant del senyor Rey, de su canceller, vicecanceller e de cualesquiere otros oficiales et aquél presentado en las ditas capliencas, canceller e fazer absolución e relaxar e prometiendo de haver pacificación et dius obligación de todos sus bienes mobles e sedientes havidos e por haver.

Testes, Jayme de Heredia e Jentó Farfí, judío Osce.

10

1461, diciembre 13. Huesca

Jehudá Alentienz recibe 2.000 sueldos de Ramón de Sangüesa de una comanda.

AHPH, notario Antón de Bonifant, prot. 347, fol. $127 r$

Albarán fazient por Ramón de Sangüesa.

Sea manifiesto a todos que yo, Jeudá Alitienz, judío, habitant en la ciudat de Huesca, de mi scierta sciencia, atorgo aver avido e en poder mío, en contantes de mano a mano recibidos de bos el honorable don Ramón de Sangüesa, ciudadano de la ciudat de Huesca, todos aquellos dos mil sueldos dineros jaqueses ... por los quales vos érades obligado con carta de comanda, recibida e testificada por el discreto Johan de Ascaso, mayor de días ... notario ... fue en la dita ciudat de Huesca a nou días del mes de marco anno a Nativitate Domini $\mathrm{M}^{\circ} \mathrm{CCCC}$ quintagésimo nono ... en poder mío de vos dito Ramón los ditos dos mil sueldos ... de la dita comanda ... yes sacada en pública forma ... por el notario infrascripto e en la nota sía cancellada ... Esto fue feyto en la ciudat de Huesca, a tretze días del mes de diziembre, anno a Nativitate Domino $\mathrm{M}^{\circ} \mathrm{CCCC}$ sexagésimo primo. 
Testes fueron a las sobreditas cosas presentes Audet de Berges e Jentó Farfí, judío sastre, habitantes en la ciudat de Huesca.

\section{1}

1464, noviembre 18. Huesca

Jehudá Alentienz vende a Johan Alamán, escudero, unas casas y corral francos, en el barrio de los Aldarbes de Huesca, por seiscientos sueldos dineros jaqueses.

AHPH, notario Martín de Trist, prot. 11.766, fols. Ir-6v

[ $1 r$ ] Jehudá Alitienze, judío, habitant Huesca. De mi cierta sciencia ... Atendient que por privilegios e concesiones reales atorgados e atorgadas a las aljamas reales del regno de Aragón y a los singulares de aquéllas yes dado e atribuydo permisso, licencia e facultat qualquiera d'ellos o d'ellas de poder vender e alienar los bienes de las ditas aljamas e de los singulares de aquéllas e de qualesquiere d'ellos e d'ellas toda ora e cada e quando a las ditas aljamas e a los singulares de aquéllas e de qualesquiere d'ellos e d'ellas plazerá e bien visto será, así cristianos e otras a qualesquiere otras personas segunt quienquiera e otras cosas más largament constan e parecen, por tenor de los ditos privilegios a los quales me refiero e aprés de los ditos privilegios e concesiones reales las ditas aljamas e los singulares de aquéllas haver costumbrado e seyer en dreyto uso e possesión sienes otra ninguna o licencia ni permisso de vender e alienar los bienes suyos e de las ditas aljamas. Por tanto, por el poder, licencia e previlegio dado e atribuído, así como singular de la dita aljama de los judíos de la ciudat de Huesca en los ditos privilegios e concesiones contenidas e atorgados, de poder vender mis bienes e qualquiere partida de aquéllos de mi scierta $[l v]$ scienca e agradable voluntat ... vendo ... a titol de pura, perfecta e acabada vendición ... a vos ... Johan Alamán, scudero habitant en la ciudat ... unas casas e corral contiguos que yo he francos ... sitiados en la judería de Huesca en el barrio de los Aldarbes, que confrontan con casas de Acach Argellet de dos partes, con casas de Abrayme Alentienz, mayor, quondam e carera pública ... $[2 r] \ldots$ por precio ... de seyscientos sueldos dineros jaqueses ... realment e de feyto recebido ... de vos Johan Alamán ... et al beneficio de dividir l'acción et de nueva e viellya constitución e a l'acción en feyto e cognición. E si en causa et ad aquella ley o dreyto que ayuda e socorre a los decebidos e enganyados en las vendiciones feytas por menos de la mitat del justo precio et de no seyer feyta la present vendición legitimament et a 
qualquiere otro dreyto canónico o civil, fuero, uso, observancia e costumbre del regno de Aragón ... que a mí, dito Jehudá, vendedor, podiesen ayudar ... o a vos, Johan Alamán, comprador, o a los vuestros contrastar o nozer en tiempo alguno ... $[2 v] \ldots$ transfiero todos mis dreytos ... me obligo ...

[3r] ... Yo, Johan Alamán, scudero habitant en Huesca ... do ... libro a trehudo perpetuo ... a dreyto enfithéotico, con comisso, fadiga ... a vos Jehudá Alentienz, judío habitant en Huesca ... unas casas e corral mías e mío contiguos que yo tengo francas e quietas, franco e quieto ... en la judería de Huesca, en barrio de los Aldarbes que confrontan ... tener mellyorados, firmes de aldezar de paretes, cubiertas e de terrados et el corral bien tapiado. Ytem, pagues ... cada anyo quaranta cinquo sueldos dineros jaqueses ... por Santa Caterina de noviembre o quatro meses aprés ... día diado ... las ditas casas e corral ... querredes vender, permutar, camiar o alienar ... siades tenido notificarlo a mí, Johan Alamán, o a mis herederos ... diez días antes de la vendición o alienación ... e notificar el precio verdadero qu'ende trobaredes e vos darán. Et si comprar o retener sanos las querremos o lo querrán que los podamos e lo podamos haver o retener en nos cinquo sueldos dineros jaqueses, menos de precio verdadero ... si no lo queremos que pagades a mí, Johan Alamán ... podades vender ... observen cada unas cosas e condiciones en el present contenidas. Item ... si no complidas las condiciones en el present contrato ... en el dito caso yo, Johan Alamán ... por nuestra propia actoridat e sienes sentencia, licencia e mandamiento de algún judge ecclesiástico o seglar nos emparemos ... de las ditas casas e corral ... podamos hacer a propias voluntades como cosa nuestra propia ...

Feyto en Huesca a diez y nou días de noviembre, anno ... milésimo quatuorcentésimo sexagésimo quarto. Testimonios fueron García Mayayo, baxador e Symuel Avingastón, judío, habitant de Huesca ...

[5r-6v] Seyer vos tenido siempre de buena salvedat, legítima garantía, firme evicción e leal defensión de la present bendición e de las cosas en aquélla contenidas, según fuero e la buena constumbre de Aragón. Et si pleyto ... sobre las ditas casas e corral o partida alguna de aquéllas ... dar vos otras tan buenas casas e corral ... por el precio que de vos he recibido ... por fianz ... obligo ... una tienda mía franca ... en la placa de la Alquibla ... Fue feyto en Huesca a diez e hueyto de noviembre, anno a Nativitate Domini millésimo quatuorcentésimo sexagésimo cuarto. Testimonios fueron d'esto García Mayayo, baxador, e Symuel Avingastón, judío, habitantes en la dita ciudat de Huesca, clamados e rogados. 
1464, noviembre 18-1467 diciembre 4. Huesca.

Johan de Alamán da a trehudo perpetuo la casa y corral que eran de Jehudá Alentienz, por cuarenta y cinco sueldos dineros jaqueses al año, con carta de gracia.

AHPH, notario Jayme de Ara, prot. 101, fols. 143v-144v

[143v] Die XVIIII novembris e anno quo supra. Yo, Johan Alamán, escudero, habitant en Huesca, certificado ... do e luego libro a treudo perpetuo ... a vos Jehudá Alentienz unas casas en la judería ... barrio de los Aldarbes ... confrontantes con casas de Acach Argelet de dos partes, con casas de Abrayme Alentienz, mayor de días, quondam e con carrera pública. Empero con las condiciones infrascriptas e cada una d'ellas. Primerament que vos, Jehudá siaes tenido tenerlas ditas casas millyoradas ... Ytem más, a pagar a mí, dito Johan Alamán ... quarante e cinquo sueldos dineros [144r] jacceses de trehudo perpetuo ... Et con esto quiero que hayades las ditas casas e corral por vuestras e como vuestras ... por dar e vender ...

Testes, García Mayayo, baxador e Simuel Avingastón, judío habitant Osce.

[144r] Die IIII mensis decembris et anno a Nativitate Domini $\mathrm{M}^{\circ} \mathrm{CCCC}$ sexagésimo séptimo, Osce. Yo, Gilbert Redón, senyor de Ponpién Muçó así como procurador qui so de los executores del último testament de don Johan Alamán, atorgo haber recebido de los executores del último testamento de Jehudá Alentienz, son a saber, todos aquellos seyscientos sueldos dineros jacceses por los quales el havía vendido al dito Johan Alamán unas casas en la judería de la dita ciudat. Et aprés se les oviese dado a trehudo et le oviese atorgado gracia de poder quitar aquéllos por precio de seyscientos sueldos. Por tanto, quitando aquéllos los herederos de Jehudá por dito Gilbert aviese cancelado.

Testes, Bernart de Cederich et Eliécer Adder, judío Osce.

[144v] Carta de gracia del dito Jehudá.

Eodem die, Osce. El dito Johan Alamán reconosció e atorgó de gracia special a Jehudá e a sus herederos ... que cada e quando el querrán comprar, si quiere recomprar del dito Johan Alamán ... causa dreyto o acción del los 
sobreditos quarenta e cinquo sueldos, del sobredito treudo, de venderles aqueélos por precio de seyscientos sueldos dineros jacceses. Ensemble con qualesquiere dreytos a él pertenescientes en las ditas casas, de no vender, transportar, el dito treudo a persona alguna et si lo fazía, quiso que valor alguno no haviese dius obligación. Testes qui supra.

13

1465, enero 30. Huesca

Lista de los judios que juran en la sinagoga, ante el bayle, de no «prender» ganancia ni prestar por mas de cuatro dineros por libra.

AHPH, notario Juan de Ascaso, prot. 200, fols. 18r-v

[18r] Jurament con la halmulacauda en la sinoga mayor de la judería.

Die predicta, en la sinoga mayor de la judería confronte, en presencia del honorable D.Miguel Jayme de Figuerola, lugarteniente de bayle, por D. Guillém Jayme de Figuerola, bayle de la ciudat de Huesca, guada por rabí Simuel Leví, judío, juroron los que se siguen de no prehender logro de ningunas cuantías que darán, ni prestarán más de quatro dineros por livra dius pena de hérem y nidduy los que se siguen:

Primero, juró Acac lo Nieto, Abray Xuén, Acac Argelet mayor, Acac Alfrangí, maestre Abram Husiello, Abrayme Alintience, Salamón de las Ynfantas, fillo de Jucé de las Ynfantas, por sí e como procurador de Jamila Xuén, Salamón Hambrón, Mossé Hambrón, Vidal Bienviniest, en su nombre propio e como procurador de Duenya Alazar, Simuel Argelet, Jucé de las Ynfantas, Haym Hamín, prestón por sí e como procurador de maestre Vidal Cap, Acac Cucumbriel e Jeudá Alitience, judíos, los quales por satisfer al fuero prestoron el jura[ $18 v]$ ment sobredito requiriendo a mí, notario infrascripto, que ende feziesse carta pública. Presentes testes fueron maestre Alfonso de Planciencia e Acac Hayeno, judío Osce. 
1465, abril, 17 y 19. Huesca

Jehudá Alintienz se queja ante el justicia y jurados de que es objeto de persecución por algunos cristianos. Le garantizan protegerlo, por ser «regalías del señor Rey» y adelantado de la aljama, pero a condición de que les diga quiénes son los cristianos que lo quieren dañar. Él no sabe quienes son los perseguidores y renuncia a su queja.

AHPH, notario Antón de Bonifant, prot. 289, fols. $20 v$ y $21 v$

[20v] Die XVII aprilis, Osce. Los senyores don Martín de Sangüesa, justicia, don Martín de la Cambra, prior, e don Jaime Gómez, jurados, dizieron a Jeudá Alitienz que como el dito Jeudá aya intimado a ellos que sciertos christianos lo hayan sitiado, así de pie como de a caballo, hayan asitiado en la casa e encara lo hayan esperado una e muytas vezes por dampnificarlo. E como los jodíos sían regalías del senyor Rey e sinyaladament como el dito Jehudá sía adelantado e oficial en el anyo present de la dita judería, que ellos no pasarían ésto sinse punición strago que lo requirieron. Demandan de part del senyor Rey, jus pena de mil florines, aplicaderos a los oficiales del senyor Rey, que él les diga quí son los ditos christianos, porque los ditos oficiales hí puedan preveyr judicialment e porque las regalías del senyor Rey sían confiadas. Jeudá non consintiendo en las protestaciones infrascriptas antes senda apella al senyor justicia d'Aragón e non claudatur. Testes, Johan de Marcén, lugartenient de calmedina e Martín de Sant Vicient. Carta pública requerida facer por Jeudá Alitienz.

Die predicta, el dito Jeudá requirió a los ditos oficiales que él no se clama de ninguno e los requiere que no y fagan res ni cosa alguna en el dicho fecho, que no tiene clamo de ningún. Testes qui supra.

Aprés acto continuo bel quasi, así los ditos oficiales como el dito Jeudá avioron por renunciados todo los sobreditos actos fechos el present e sobrescripto día de aquí a suso en la present plana e requirieron a mí, notario, que lo cancellase. Testes, Johan de Marcén e Vicient Navarro, Osce.

Die predicta, los ditos oficiales e don Martín de Araus más que sobrevino, mandoron al dito Jeudá, cara a cara, que, como a notizia suya, fuese prevenido que sciertos christianos así de pie como de cavallo aviesen esperado al dito Jeudá una, dos, tres hi quatro noches por dampnificarlo, que le 
mandaban como de feyto le mandaron que d'aquí a después le muestrase información e les dixiese quí eran e el dito Jeudá dixo que le plazía. Testes qui supra último, Osce.

[2Iv] Die XVIIII aprilis, Osce. Jeudá Alitienz, judío Osce, dixo que a hun mandamiento a él feyto por los senyores prior hi jurados de la ciudad de Huesca, segund del dito mandamiento consta por carta pública, testificada por mí a XVII del present mes que responde qu'el día de Pascua primera pasada de christianos e el día antes e el lunes siguient en la noche, la una noche lo corieron con capas, los quales no conosció e ellos o otros lo speroron el lunes aprés Pascua e stieron grande noche allí, segund por relación de su cosín Abrayme, e Salamón supo e lo vió por la finiestra, pero que no los conosció ninguna. Et otra noche lo speroron IIII $^{\circ}$ segund relación de Aym Almaxech e encara se dexoron d'ir a la finestra esta adupería aver mala noche esta noche, pero non deconosció ninguno. Aprés a treballado saber quí eran e ninguna con verdad lo ha podido saber. Testes, Bernart de Luch e Acach Alintienz, judío Osce.

1465, julio 11, 16 y 20. Huesca

Información en la muerte de Jehudá con la lista de testimonios, tanto cristianos como judios. A la información se añaden tres escritos: [1] petición del notario Johan Beltrán que pide la libertad del matrimonio judio Azerián Xuén y su mujer Oro; [2] orden del justicia para que Rodrigo d'Escasiella se presente ante el concejo en el plazo de ocho días; y [3] escrito de exculpación de Rodrigo que presenta dos testigos que dicen que él estaba en Bardanena el día del asesinato.

AHPH, notario Antón de Bonifant, prot. 289, fols. 60v-61v, 62v, 65r y $67 r$

[60v] Información en la muerte de Jeudá.

Die XI juli Osce. Don Martín de Sangüesa, justicia, e don Jayme Gómez, jurado, prendioron la información diuso scripta.

Primerament Audans, teste jurado, responde e dize que no y sabe res.

Acach el Nieto, jodío teste jurado, responde e dize que un día del mes de junio bino Jeudá Alitienz, judío, delant él como judge que yes de la aliama 
de los ditos jodíos de la ciudat de Huesca, requiriéndolo que'l fiziese de manifiesto las notas de Jucén Papur, judío e notario de jodíos, como hí haviese algunos actos pertenescientes al dito Jeudá e encara tocantes intereses del senyor Rey. E de feyto el dito deposant como judge contreyto por el dito Jeudá fue a casa del dito Papur e le manifestó las ditas notas e las traxo a su casa e depués a poco rato bino el dito Papur al deposant diziendo que tomase las escripturas que fazerán por Jeudá e por el senyor Rey e las otras le dase por que las gentes me demandarán las otras. E el dito Jeudá era allí. E malignoso l'uno contra l'otro, e se dixieron de feas paraulas. E el dito Jeudá demandó segura del dito Jucé Papur, e de feyto el dito Jucé dixo que no lo siguraría porque él era enemigo suyo de sangre e que no lo seguraría. E el deposant, como judge, non obstant sus razones, él le mandó que sigurase e él priso tiempo a fazer la dita segura e aprés vino sentimiento que en este medio el dito Papur fue a favlar a don Sancho López. E aprés, vino a segurar e seguró. E aprés, uvo sentimiento el dito deposant que comprometieron en poder del dito de don Sancho López e aprés espiró el dito compromis. Él no y sabe más, pero creye segund las conginturas, creye qu'este Papur meresce culpa en la muert del Jeudá e tal fama pública yes en la ciudat de Huesca.

Jacó Choén, teste jurado, responde e dize que hun día del mes de mayo o de junio primo pasados, este Jucén Papur desafió al Jeudá e a poco rato uno a caballo sobre hun ginet, con hun otro ginetario quiso matar al dito Jeudá, sino por que lo avisoron d'esto, todo vió e oyó el deposant. Aprés sintió que se ficavan compromis [61r] en poder de don Sancho López e porque él no quiso firmar martes a la tarde, lo mataron el miércoles en la manyana et que creye verdaderament que a tracto d'este Papur yes muerto Jeudá e qu'él s'ende notará con qui quiere.

Don Johan de Ascaso, teste jurado, responde e dize qu'el deposant como notario, intervino en firmar compromís entre el Papur e Jeudá. E aquel compromís espiró. Aprés, se tractó entre ellos que tornasen a firmar e de feyto el martes más cerca pasado a la noche, don Ramón de Sangüesa invió a clamar al deposant e le dixo testificar hun compromís aquí de Jeudá e después yrez al otro e firmará e testeycó testificó el comproment de Jeudá e fue aprés al otro, e no quiso firmar, antes dixo que no y sabía res, pero que consultaría con sus amigos e qu'él se vendría a su casa, pero que creye que segund las conginturas creye que el Papur haya cabido.

Maestre Bernart de Arás, teste jurado, dize qu'él bien sabía que avía zizanias entre Jucén Papur e Jeudá, e que avía oydo dezir al Jeudá qu'él se 
rezelava muyto de Rodrigo de Scasiella, ferero de Bardanena. E aprés, el domingo antes del día que matoron al dito Jeudá él lo trobó a Sant Miguel con espada e hun punyal en mal son e díxele el deposant: - ¡Tú en mal son bas! ¿Qué fas por aquí? ¡Guárdate de mal $_{i}-$. E aprés, el lunes siguient lo trobó que cenavan a la noche él e hun otro en casa d'Andás e así mesmo le dixo: -iQué cosa que tú vas a la sombra de los terados!-. E que sabe que traya hun sayo cárdeno. E vió más, e que tenían dos dobleras de pan e qu'ende comproron huni otra doblera.

Martín Escudero, teste jurado, dize que encontró a Rodrigo de Scasiella, ferero de Bardanena, e hun otro pastor o erbathant de Castillón de Sieso por la judería en mal son e dixo el deposant: -Vosotros ¿qué fiz aquí a esta ora?-. Dijo el ferero de Loare: -Azerián Xuén, que tiene hun compromís con mí e era en poder de Sancho López, e no nos avenimos e viengo por si remedio e por salvarlo-.

[61v] Don Ramón de Sangüesa, teste jurado, responde que de la muert de Jeudá no y sabe, sino que ha oydo dezir qu'el ferero de Bardanena, fillo del ferero de Loare, lo ha feyto. Es verdat que sabe que avía sciertas diferencias entre Jucén Papur e Jeudá Alitienz e sabe qu'ende firmoron compromís en poder de Sancho López e de Ramón de Xixena. E porque no quisieron prorrogar el dito compromís, el Sancho López n'estava mal contento de Jeudá e es porque se dizía l'avía ofrescido el dito Jeudá lexarlo en poder del dito don Sancho López si el Papur lo y lexava. E que agora el dito Papur lo y lexava e no quería el dito Jeudá porque le bariava lo feré stido el dito Jeudá al dito don Sancho López. A oydo dir el dito deposant qu'el dito don Sancho López lo tenía en mala openión e que algunas gentes suyas lo querían danyar. Si lo fazerían de mandamiento de don Sancho López o no, que no lo sabe, e el dito Jeudá, havido sentimiento por terceras personas, que gentes del Sancho López, segund a él dizían, lo querían danyar. Huuo recurso al dito deposant e lo rogó qu'él deviese yr al dito don Sancho López a rogarlo que las diferencias que eran entre el Papur, que las deviese apartar e esviar hi el dito deposant. Fue el lunes más cerca pasado al dito Sancho López e lo rogó que las ditas diferencias, por amor d'él, quisiese sacar e concordar hi el dito Sancho López. Dixo al dito deposant que el dito Jeudá lo avía burlado hi dádole algunos cargos e bariádole la palavra que l'avía dado e que no tomás'enoyo el dito deposant, qu'él no y quería intervenir. Hi el dito deposant lo tornó a rogar e suplicar qu'ende quisiese prender cargos de tirarlos de questión. Hi la ora, el dito don Sancho López, por amor del dito deposant, dixo que era contento, hi concordoron que todas la 
diferencias hi questiones de los sobreditos Jeudá e Papur venisen en poder del dito don Sancho López e de Ramón de Xixena hi el dito deposant, el martes siguient, fizo comprometer las ditas questiones en poder de los sobreditos mediant acto público, testificado por Johan de Ascaso. Hi el dito deposant dixo al dito notario que pues que el Jehudá avía firmado que y sea al dito Papur qu'él fuera por lo semblant e el dito notario hí fue al dito Papur e le firmó lo sobredito. E según el notario dixo al dito deposant, el dito Papur no quiso firmar, antes se tuvo deliberante. Es verdat qu'el día qu'el dito Jeudá comprometió el dito deposant estando yantando, vino el dito Papur al deposant e le dixo: -iMonseyor, yo so destones que os visito camal!-, hi otras palavras con esas. E al finquar, le dixo: -¡Mosenyor, con don Sancho López vos sez visto!-. Dixo el deposant: -¡Sí, hi le rogado que las diferencias vuestras hi de Jeudá que las tire hi ha [62r] concordado con el que entramos! ¡ Vosotros finez vuestras questiones en poder del dito don Sancho López e de Ramón de Xixena, segund que primero aviaz comprometido, hi creo que muy presto él vos concordará si yo y seré necesario por amor de vosotros y mí dispondré! Repuso el dito Papur: -¡Por mi fe, senyor, de muyto mal paso a saviez sacado al dito Jeudá, hagora l'a vez feyto hun gran beneficio, que no sabez de qué lo sacaz agora, que por muyto que lo ayaz sacado de malos lugares agora lo sacaz de mayor, ahunque pesar mía de su danyo por el bien que lo quiero!-

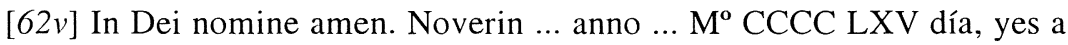
saber, tretze del mes de julio, en la ciudat de Huesca ante las personas ... Martín de Araus, jurado e lugartenient de prior de jurado, e don Martín de Garapún, jurado de la ciudat de Huesca, en el anyo present e suso scripto e presentes mí, notario, e los testimonios diuso nombrados comparesció ... Johan Beltrán, notario ... de Huesca, así como procurador qui se dixo de Azerián Xuén, judío ... de la ciudat e de Oro Xuén, muller suya, el qual dixo ... yo, como procurador de Azerián Xuén e de Oro Xuén, ... vos demando a vos e vos suplico me digades por qué fueron e son presos los sobreditos mis principales en la cárcel común de la ciudat de Huesca. E los ditos jurados respondieron que porque los oficiales de la dita ciudat binieron suspecto qu'ellos huviesent capido en la muert de Jeudá Alitience. E por exa razón el procurador de la ciudat de Huesca apellidó contra los ditos Azerián e su muller e otros e por virtud del dicti apellido fueron presos ellos hi otros e aprés de su prisión, los oficiales han tomado información por virtud de los statutos de la ciudat. E aprés de la información, [63r] han mandado clamar el consello de la ciudat, el qual fue plegado a XII días del dito mes de julio, anyo suso scripto, en el qual concello fueron leydas las 
informaciones que los oficiales avían preso sobre la muert del dito Jeudá por saber quí eran culpables e por qué, por la dita sumaria información, no son trobado culpables en cosa ninguna de la dita muert los sobre ditos Azerián ni su muller. El dito consello de la dita ciudat a deliberado que contra los ditos Azerián ni la dita su muller, pues que se troban inmunes de la dita muert, no faga part el dito procurador de la dita ciudat ni los acuse rialment, antes reverencie el dito apellido e requieran al justicia de Huesca devant de qui contra ellos apellidado, que aquéllos livre de la capción en que a instancia suya están presos e por él más no los detenga. E requesta la qual renunciación, por birtud del dito consello e por mandamiento suyo e de los otros jurados, el dito procurador de la dita ciudat fizo, delant el dito justicia, segunt de la dita renunciación e aquesta consta por carta pública que feyta fue en la sobredita ciudat de Huesca, a XII días del dito mes de julio, anyo suso specificado, recibida e testificada por el notario diuso scripto. Et el dito Johan Beltrán procurador, aserto suso especificado, dixo que requería, segund que de feyto requirió, a mí, notario, diuso scripto, que de todas e cada unas cosas sobreditas e de cada una d'ellas l'inde fiziese e testificase carta pública una e muytas e tantas quantas necesitase e huviesse él e los ditos sus principales a conservación de sus dreytos. Testimonios a las sobreditas cosas presentes fueron Pedro de Gan e Bertholomeu Mirot, bezinos, si quiere habitadores de la ciudat de Huesca.

[65r] Die XVI, julii, Osce. Don Martín de Sangüesa, justicia, don Martín de Garrapún, don Jayme Gómez e don Sancho d'Aso, jurados. Seguroron la persona de Rodrigo d'Escasiella, ferero de Bardenena, que dentro ocho días pueda venir a scusarse, si scusarse puede, de la culpa que le dan en la muert de Jeudá Alitienz, en tal manera qu'el dito ferero pueda venir delant los ditos oficiales dentro el dito tiempo. Seguro que por el dito caso ni otro alguno no le ocuparán su persona, en tal manera que quando él stará reputado delant los ditos oficiales e avrá fablado con ellos e ellos le dirán que se vaya a su casa, que dos días aprés le cora el tiempo de la segura, no más, porque ayan tiempo de yr a su casa. Large. Testes, Ramón de Sangüesa e Martín de Arnedo, coredor de orella.

[65v] En el feyto de Jeudá.

Die XVII julio, Osce. Don Martín de Sangüesa, justicia, don Martín de la Cambra, prior, Gómez Asso fue presa la información diuso escripta por virtut de los Statutos.

Aym Figel, teste jurado, interogado sobre la muert de Jeudá que hí sabía. 
Responde por el jurament que ha feyto, que sobre este fecho ya ha deposado en poder de Martín Navarro, procurador fiscal, e Bardaxín, notario, que se refiere a la deposición que ha feyto.

Nicín Sanogo nichil.

Acach de Pina, teste jurado, e por el jurament interogado, responde e dize: -El día antes que morise, que a la tienda del deposant s'aplegó Abrayme Alintienz e otro e entroro en [ilegible] de Jehudá Alentienz e dixo Abrayme Alintienz: ¡Más baldría que Jeudá Alintienz morise a mano de sus parientes, que no a manos de un lacayo! E respondió Jucé Papur: ¡No digaz mal de Jeudá devant de Acach de Pina, que mucho yes amigo suyo!-. Interogado si sabe quí lo mató, responde que no, que oyó dizir al talím en la carnicería, devant Johan de Avay, que fama era qu'el fillo del ferero de Loarre lo avía muerto.

Nicín Anín, alias Cubero, teste jurado, responde e dize que sábado a más cerca pasado, antes que matasen a Jeudá, qu'el deposant hi Figel hi Mosé Cohén estavan a la Portaca del Alderbe, cango cerrado el güerto de don Ramón de Sangüesa, así a ora décima, e que vieron al fillo del Blanco que favló con el fillo de ferero de Loarre e con hun otro que en su companya era. E aprés el fillo del Blanco fue a clamar a Salamón Alintienz. E aprés entramos, favlaron con el fillo del ferero de Loarre, vestido de cárdeno. De lo que favlaron, que no sabe, e que bió qu'él, vestido de burel, s'entró por la puerta de Acach Argelet e por fama que aquél, vestido de cárdeno, a muerto a tracto de Jucén Papur e de Azerián e de su muller e de los otros sia [66r] nombrados. E por fama oyó dezir qu'este Salomón Alintienz lo avía corrido con la capa gorga.

Astruch Cazez, teste jurado, dize que vió muerto a Jeudá Alitienz e que ha oydo dezir que lo ha muerto el fillo del ferero de Loarre. E que ha oydo dezir, que Rabí Jucén e el fillo del Blanco e Salamón Alitienz hí han cabido en tracto, e que sabe qu'este fillo del ferero de Loare favla con el fillo del Blanco e Abrayme Alitienz el sábado antes que no matasen al dito Jeudá. E aprés que uvieron favlado, pasoron los ditos fillos del dito ferero de Loarre e hun otro, paşoron buena estonda por la judería, uno por acá e otro por allá. Más sabe el dito deposant, qu'el domingo antes que matasen al dito Jeudá, el dayán tenía cort e vino Jeudá e posóse cerca el dayán e dixo: - ¿Parésceos bien, don dayán, que de casa de Martín de Ordás d'aquí, a casa de don Ramón de Xixena me a corido mi nieto Salamón Alintienz con la capa gorga rancada por quererme matar? Porque vos suplico me fagaz 
segurar d'él-. E, en esto, díxole el dito dayán al dito Jeudá:-¡Por buestra fe, pase agora!-. Replicó e dixo el dito Jeudá: -¡Paresca como vos me lo rogays e yo so contento!-. E el deposant asímesmo, le dixo que pasase por aquella vez e pasó e más sabe que le dixo Mayr Xuén que avía dito el dito Salamón por el dito Jeudá:- ¡D'aquí a avant, no y a otro remedio sino rancarlo del mundo el día mesmo!-. E que Rabí Jucén le dixo al deposant, estando en una [ilegible] que en toda manera del mundo, este Jeudá avía de morir e que no hí avía otro remedio. E aprés, vió favlar al dito rabí Jucén con un escudero de Sancho López de Latrás, e que sabe qu'el Blanco hi Abrayme Alintienz e el rabí Jucén favlavan muchas bezes todos tres.

[67r] Testimonios producidos por parte de Rodrigo d'Escasiella.

Día XX, julio, anno a Nativitate Domini, MCCCCLXV, Osce, don Martín de Sangüesa, justicia, don Martín de la Cambra, prior, don Jayme Gómez, don Martín de Garapún e don Sancho d'Asso, jurados, a instancia de Rodrigo d'Escasiella, ferero de Bardanena, prendioron información diuso scripta y dizieron en testimonio.

Sancho d'Ara, bezino d'Ara, teste jurado, e por el jurament interogado, responde e dize el dito deposant qu'el día de los fratres, biéspera de San Benedet, e visto que era fiesta, fue a Vardanena e plegó allí a sol salido. El dito día levó una rella e la dió al dito Rodrigo d'Escasiella, ferero sobredito, de su mano a la suya dentro, en el lugar de Bardanena e en su casa e ella prendió.

Guiralt Marta, bezino del lugar de Bardanena, teste, responde e dize que qu'el miércoles, vespra de San Benedet, primero pasado, el deposant era en Bardanena; en la mañana él lo oyó feriar en su casa pero no lo bió e aprés fuese de a su lavor a segar. Aprés tornó a hora de comer e los vió segar con su muller en el campo e aprés le favló en la tardada e aprés, el jueves, el dito ferero sinde fue al mont. E el dito ferero requirió a mí, notario, diuso scripto que de las sobreditas cosas l'ende fiziese carta pública.

Testes, don Ramón de Sangüesa e García d'Agüero, Osce. 
RELACIÓN DE LOS JUDÍOS QUE FIGURAN EN EL APÉNDICE DOCUMENTAL ${ }^{24}$

Adder, Eliécer, 12 [70]

Adida, Mosé, 4

Alazar, Duenya, 13

Alcastiel, Jucé, 6

Alentienz, Abrayme, 11 [33]

Alentienz, Abrayme, 12

Alfrangí, Acac, 13

Alguer, Acac, 4, 5, 7 [37]

Alintienz, Abrayme (primo de Jehudá), 14

Alintienz, Abrayme, 15 [89]

Alintienz, Acach, 14 [58]

Alintienz, Salamón (primo de Jehudá), 14

Alintienz, Salamón, 15 [59]

Alitience, Abrayme, 13 [33]

Alitience, Eleazar, 4

Alitienz, Jehudá, 1-15

Almaxech, Aym, 14 [32]

Almaxech, Jeudá, 4

Altixifí, Abrayme, 2

Ampinaz, Alazar, 9

Anín, Nicín, alias «Cubero», 15

Anocha, Jacop, alias De las Infantas, 2

Argelet, Acac (mayor), 13[49]

Argelet, Acach, 11, 12 y 15 [49]

Argelet, Simuel, 13

Arueti, Semptó, 3 [34]

Avinardut, Bonadona (viuda de Baruch Alentience), 3, 4 y 6

Avingastón, Symuel, 11 y 12 [110]
Avinjafia, Simuel, 9

Aybarí, Hacén, 6

Bienviniest, Vidal, 13

Cap, Vidal (maestre), 13

Cavatierra, Sentó, 6

Cazez, Astruch, 6 y 15

Cohén, Jacó, 2 y 15 (su viuda en

[66])

Cohén, Mosé, 15

Cucumbriel, Acac, 13

El Nieto, Acach (juez de la aljama), 15

Exuén, Azarián, 6

Farfí, Jentó (Sastre), 9 y 10 [8]

Figel, Aym, 15

Gastón, Aym, 8 [109]

Hambrón, Mossé, 13 [88]

Hambrón, Salamón, 6 y 13 [117]

Hamín, Haym, 13

Hanayut, Salamón (de Calatayud), 9

Hayeno, Acac, 13 [86]

Husiello, Abram (maestre), 13 [74]

Infantas, Jucé de las, 13

Infantas, (hijo de Jucé de las), 13

Leví, Cazón, 6

Leví, Simuel (rabí), 13

Lo Nieto, Acac, 13

Natán, Gentó, 6

Papur, Jucé (rabí, notario de judíos), 15

Parexo, Simuel, 4

Pina, Acach de, 15 [19]

24 Se remite al número de documento del apéndice. La numeración que figura entre corchetes corresponde al número de la nómina de casatenientes de la judería en 1475, publicada en Sefarad 63 (2003) págs. 227-236 
Rahenas, Jucé, 4 [31]

Rondí, Mossé, 9

Sanogo, Nicín, 15

Xuén, Abray, 13

Xuén, Abrayme, 3 y 6

Xuén, Acac (fillo de Abrayme
Xuén), 6

Xuén, Azerián, 15

Xuén, Jamila, 13

Xuén, Jucé, 6

Xuén, Mayr, 15

Xuén, Oro (mujer de Azerián), 15

\section{RESUMEN}

Exposición relativa a las actividades de Jehudá Alitienz de la aljama de Huesca, que finaliza con su asesinato a manos de un cristiano. Este fatal desenlace se debe, presumiblemente, entre otros motivos, al incumplimiento por parte de la víctima de los compromisos adquiridos con Sancho López en asuntos comerciales. A esto hay que añadir como circunstancias coadyuvantes la enemiga de rabí Jucé Papur, así como el enfrentamiento de la víctima con algunos de sus propios familiares. Este trabajo nos permite conocer mejor la vida de la aljama y sus problemas internos, así como el funcionamiento del sistema judicial en la resolución de hechos criminales o de cualquier otro tipo de delito.

Palabras Clave: Historia de los judíos, Aragón. Baja Edad Media, crimen.

\section{SUMMARY}

The present article deals with the life of Jehuda Alitienz in the aljama of Huesca and his murder at the hands of a Christian. The reason for his tragic death is presumably to be sought in the non-fulfillment of a business agreement he had concluded with Sancho López. Other circumstances, however, may have played their part as well such as Rabbi Juce Papur's unfriendliness and the victim's tricky relations with some members of his own family. In studying this case we hope to throw some light on the life and the problems that could arise in an aljama as well as on the local judicial system, especially in the area of crime.

KEYwORDS: History of the Jews, Aragon, Laste Middle Ages, crime. 